2006-01-08-1

MAY 31, 2006

\title{
CHEATER, CHEATER, PUMPKIN EATER: DEALING WITH CHEATING IN A LARGE CLASS
}

\author{
“Should I give Kathy Careless a -50 for breaking the academic integrity policy?”
}

Barb Warner, an Instructor in the Information Systems and Decision Sciences (IS \& DS) department at the University of South Florida (USF), pondered the difficult situation. Warner's academic dishonesty policy was very explicit. She had detected two projects submitted by students in her ISM-3011 course that were copies of each other. Her policy was that both parties were to receive disciplinary action. Kathy begged not to lose the points and insisted that she didn't cheat. She claimed she had done all of her own work. Warner confronted Bobby Busted, owner of the other copy, and he made the same claim.

As part of her subsequent investigation, Warner found that Kathy had completed her project in one of the public labs in her apartment complex. She admitted that she had not emptied the recycle bin on the computer on which she had been working. She didn't think her punishment was fair but was more concerned about who copied her project. She didn't know Bobby. Warner had a feeling that Kathy was telling the truth but didn't feel she could rely on "feelings" alone. After teaching several large classes she could more or less sense who was, and who wasn't, telling the truth. When she confronted Bobby again, he admitted to copying Kathy's project from the apartment complex computer.

Warner informed Bobby that the consequences of his dishonesty went beyond her class. It seemed that Kathy's mother was a lawyer and they wanted Bobby's full name because they were going to bring a lawsuit against him.

\footnotetext{
This case was prepared for the purpose of class discussion, and not to illustrate the effective or ineffective handling of an administrative or classroom situation and is copyrighted by the Informing Science Institute. Permission to make digital or paper copy of part or all of these works for personal or classroom use is granted without fee provided that the copies are not made or distributed for profit or commercial advantage AND that copies 1) bear this notice in full and 2) give the full citation on the first page. It is permissible to abstract these works so long as credit is given. To copy in all other cases or to republish or to post on a server or to redistribute to lists requires specific permission and payment of a fee. Contact Publisher@InformingScience.org to request redistribution permission.
}

This incident wasn't an isolated one. Every semester, it seemed, a new set of cheating incidents emerged. In addressing these, Warner faced a couple of challenges. She wanted to limit her student's ability to cheat without limiting their ability to learn. At the same time, she wanted to detect those who had violated her academic dishonesty policy. Achieving both goals was extraordinarily difficult for a large class. 


\section{Barbara Warner}

Barb Warner's career included a broad range of both business and academic experience. After receiving her undergraduate degree in Computer Science/Mathematics and her graduate degree in Management Information Systems from the University of Arizona, she worked as a systems programmer and then as a director of MIS. In 1982, she first began teaching computer science, MIS and mathematics courses at various universities and community colleges. During that period, she managed a self-paced computer science program, which used distance-learning technologies to successfully instruct approximately 600 students each year in 21 different computer science/technology courses.

Warner first joined USF as an adjunct instructor in 2001. In fall of 2003, she took a leading role in managing ISM-3011 — a large MIS undergraduate core course - a period during which the assigned instructor became ill and later died. During the spring of 2004, she was offered a full time Instructor position by the department. In that capacity, her teaching responsibilities were to include both teaching all sections of ISM-3011 and teaching an additional section of an undergraduate course, such as Electronic Commerce.

In the summer after joining USF full time, Warner participated in the USF Center for 21st Century Teaching Excellence's ( $\left.\mathrm{C}^{21} \mathrm{TE}\right) 2004$ Institute for Increments and Transformations, where she began exploring new opportunities to incorporate many new technologies into her courses - particularly ISM3011. To further enhance her perspective, she enrolled in several Instructional Technology courses offered by the College of Education at USF - including courses in web programming and a doctoral seminar that explored distance-learning research.

Although research was not an official part of Warner's instructor assignment, the size and complexity of her teaching load meant that she needed to experiment continually with new approaches. Thus, she viewed her teaching as an ongoing research process - at least from a practical standpoint. She described her particular areas of interest as follows:

The use of information systems and technology-enhanced instructional methods to increase interaction, commitment, and persistence of the students enrolled in large class face-to-face and distance learning courses.

Warner's innovative activities in the teaching area did not go unnoticed at USF. In 2005, she was awarded an Innovative Teaching Grant by USF's $C^{21}$ TE. In early 2006, she received a grant under their Innovation Teaching Opportunities Grant (ITOPP) Program, providing her with a Tablet PC to help her in offering her courses. She also presented at the USF Teaching Technologies Symposium in 2006.

When Warner was growing up, her father was an FBI agent and later he was Vice-president of Loss Prevention for a large chain of retail stores in the Washington, D.C. area. He would tell stories of the cases he worked and the people that he had caught stealing. She felt the stakes were higher for her and her sisters to not break the law than for other families. This helped form her opinion toward cheating and ethics. She described her attitudes on the matter as follows:

"Since I started teaching since 1982, I have seen many students who leave a class and can't program or do whatever skill they were supposed to learn and it bugs me that they get a $\mathrm{C}$ or Cand don't learn anything. There often isn't much that can be done. Sometimes they even tell me they didn't learn anything in a particular class but passed it. Also, several faculty members have 
informally discussed the fact that if a student gets a passing grade in a class - and then is hired by an organization and doesn't know anything about the subject/programming language/office skill - then it reflects badly on the MIS department. So that is why I do what I do here-I know it's not fool-proof and there are many ways to get around it, but it's a start and hopefully it can be improved upon in time and with experience.”

\section{ISM-3011}

ISM-3011, Information Systems in Organizations, served as an introduction to MIS for all undergraduate business majors. Because USF's undergraduate business program was designed as an upper division major (over half of USF's undergraduates took their first two undergraduate years at community colleges), it was typically taken by students in their junior year. As a core business course, it also fell under a college mandate that required all core courses to be offered in a distance-learning format, as well as in a more traditional lecture setting.

The course was designed to serve two roles: as a survey of the topics central to the MIS field and as an introduction to some of the core technologies-including databases_-that all managers could expect to encounter during their careers. As a result of this dual mission, course content and activities took a number of different forms, including:

- Readings

- Online video tutorials, prepared by Warner using the animated screen capture tool Camtasia

- Exercises to be completed (e.g., using MS-Excel, MS-Access)

- In-class and online lectures

- Extra credit discussions/case studies, both in-class and online

In a typical year, 1600 students took ISM-3011, making it one of the largest courses in the college. During spring and fall semesters, its two sections-one offered lecture style and one offered via distance learning - had combined enrollments approaching 700 students. To put these numbers in perspective, ISM-3011 enrollments exceeded the combined enrollments of all the remaining MIS courses, graduate and undergraduate, offered by the other 15 full time MIS faculty members in the department. Only one other course in the department, a core undergraduate statistics (QMB) course, had comparable enrollments. In order to manage the two large sections, Warner was assigned 80 hours/week of graduate teaching assistant (TA) time, normally split between 4 to 6 TAs enrolled in the MS-MIS program or MIS $\mathrm{PhD}$ program.

As illustrated in the spring 2006 course syllabus (Exhibit 1), the ISM-3011 was divided into modules. The modules, based around chapters in the textbook (that could be accessed online), provided discrete assessment points for the class, since distance learning students enrolled with the understanding that they would have to come in to USF four times during the semester, in order to take exams. As a consequence of this design, most grading activity was organized around the module end points.

Student grades in ISM-3011 were based upon accumulating points, with a total of 500 being possible. 200 of the points were allocated to projects. The remaining 300 were based on test performance. 


\section{Testing}

The nature of the course-roughly half of the students taking it face-to-face, with the other half taking it in a distance-learning format-made testing challenging. To ensure the rigor of testing, all students, including distance learning students, were required to take the three module tests on-campus. This meant that approximately 350 students were tested at one time.

Tests were administered in an auditorium. Earlier in Warner's teaching career, she had proctored a test for a course with about 150 students. She couldn't believe the blatant cheating and, even worse, that none of the students were trying to conceal it. People were talking amongst themselves during the test and comparing answers. Some were using their notes and one actually used his cell phone during the test. She moved people to keep them from cheating but these students couldn't believe she would do that. After all she wasn't their regular professor. This experience helped her form her methodology for giving tests. She did preparation and setup for the test to prevent cheating and, in this way, felt that she didn't have to worry as much about trying to catch students cheating during the exam.

The mechanisms put in place by Warner to discourage cheating included the following:

- Printed labels, with each student's name and ID number, were affixed to each seat in the auditorium in a manner that required students to be seated in alphabetical order. This made it harder for groups of friends, who might be tempted to copy off each other, to sit together.

- Four versions of the test (printed on different color paper) were distributed. Although the questions were the same on each test, their order was randomized, and the multiple choice answer choices were also scrambled. The colors allowed the TAs and Warner to pass out the tests in a manner that ensured students sitting next to each other didn't receive the same version of the test.

- The test was made up of 50 multiple-choice questions and one essay question. Each version of the test had a different essay question.

If students missed taking the test on test day, they were given the opportunity to take a make-up test. This test, however, was all essay questions. Warner had found that this procedure ensured maximal attendance on test day.

She also strictly enforced a number of rules:

- No book bags or notebooks at seats. Students were only allowed to take a purse and pencil with them to their seat. All other items had to be stored along the wall.

- No hats or hoods. All students were required remove their ball caps or sweatshirt hoods.

- No bathroom breaks and no leaving the auditorium at any time during the test.

- When students turned in their test, they were required to show a picture ID. Students forgetting their ID could call and have someone bring their ID to them. They were not allowed to leave to get their ID, however. It was just too difficult to keep track of who left to get their ID.

With these procedures in place, Warner felt relatively confident with respect to the integrity of her examinations. 


\section{Projects}

Projects were a different matter. Because a key objective of ISM-3011 was to acquaint students with software commonly used in business, project work constituted an important part of the class. The two most important software applications were Microsoft Excel, a spreadsheet tool used extensively for financial and general purpose computational applications, and Microsoft Access, a powerful desktop database program. The first module also included a course orientation project. Presented in the form of a checklist to be completed in Excel, the project had two distinct learning objectives. First, it served to get students used to using the technologies available for the course. They had to access information in Blackboard, navigate to the online text, log into Instant Messenger (IM) and communicate with one of the TAs (or Warner) and compose an email to be sent to the ISM-3011 email account. Second, it forced the students to read the syllabus, which included Warner's academic integrity policy. As part of the project, they had to answer questions taken from the syllabus. That way, students couldn't come back later in the semester and say they weren't aware of the policy.

During the semester, Warner required her students to complete three Microsoft Access and three Microsoft Excel projects. Each project contained a scenario simulating a business problem for the students to solve. They were given directions on what was required for the project. For example, they might be required to create 3 tables, a form, 5 queries, and a report using Access (Exhibit 2). The directions were intentionally general-rather than providing a "recipe" to follow—so students could hone their problem solving and critical thinking skills. All projects were to be done individually, a fact that was clearly stated in her academic dishonesty policy in the syllabus and in the instructions for each project.

To balance the strong stance against collaboration, Warner ensured assistance was offered to the students in a wide variety of ways. For example, the ISM-3011 staff was available for over 50 hours each week in a variety of venues: the course office, the lab, and online (Exhibit 3). Students could also use Microsoft Instant Messenger to communicate with the ISM 3011 staff during these hours, as well as meeting with them face-to-face during the office and lab hours. Also available were online tips that Warner had recorded using Camtasia, a computer-recording tool that allowed her to record her voice as well as her computer screen as she completed a wide variety of tasks using either Access or Excel (Exhibit 4). For example, one video segment demonstrated the procedure for creating an Access table, inserting its data fields and assigning appropriate the data types. The problems and datasets used for Warner's tips were entirely distinct from those used in the class projects. As a result, the tips seemed relevant to all of the projects through the semester and didn't need to be rerecorded each semester. It also helped the students to develop the ability to generalize from an example and apply it to a different situation. Students could also use an Excel or Access book for help as well as the products' online help. Given the amount of assistance students received, Warner felt justified in requiring the students to complete the projects individually.

The process of managing and grading student project submissions was extremely challenging. When Warner had taken over ISM-3011 in fall of 2003, students completed projects but the projects were not turned in or graded. The students got credit for the project by completing an online quiz to demonstrate that they had learned the material. Using this procedure, grading was much easier than actually grading the projects themselves. Unfortunately, it was evident that students were emailing each other the answers to the quizzes.

Warner felt strongly that if students were expected to devote a substantial effort to completing individual projects, they had the right to see their projects graded and returned. Her initial procedure required each 
student to submit each project in a manila envelope. Warner and her TAs then performed grading. While this process seemed substantially more beneficial from the student's perspective, it had three drawbacks:

- It was far more time consuming to grade this many projects using this new method.

- It made it difficult to detect whether a student had copied a project from another student or collaborated with a group on the project.

- It generated huge amounts of unwanted (and uncollected) paper, the disposal of which was complicated by the fact that student names and social security numbers (used to identify students at USF until 2005, when USF-assigned student ID numbers replaced them) were on each project, meaning that shredding was required.

The last of these problems proved most tractable, when Warner replaced hard copy envelopes with the Blackboard assignment feature. Using this feature, once students had uploaded their projects, the entire class could be downloaded as a single compressed (.zip) file. The individual student projects could then be extracted, graded and returned electronically. This also provided some measure of relief for the first drawback, as it was actually easier to grade software projects in electronic form.

\section{Cheating and the CCPE System}

The second problem, detecting unauthorized collaboration, was substantially more difficult to resolve. Originally, the only way to identify duplicate projects had been if the grader happened to grade two projects that were a copy of each other and then could remember which project was the duplicate. Very few duplicates ever got picked up this way. To address this deficiency, one of the TAs for ISM-3011, James McCart, came up with a way to check for duplicate projects. He discovered that an Access database had some relatively well hidden information concerning its creation stored within the database. Specifically, when an object, i.e. a table, query, form, etc, was created in Access, a read-only timestamp was created for that object. If a student copied the database file and renamed it, the original creation date of the database was still preserved as well as the original name. Using this information, he created an Access program, that he named CCPE (Cheater, Cheater, Pumpkin Eater), that extracted the type, name, and timestamp of each object (Exhibit 5). Objects with the same timestamp, names, and of the same type were flagged as duplicates. CCPE also compared the timestamps at the database level. To detect copying, the program would take all of the projects in a folder and compare each project to every other project in that folder, looking for duplicate dates and names. Even with close to 700 database projects to compare, CCPE could complete all the comparisons in less that one minute.

The detection of duplicate Excel projects had not been as straightforward. Another TA, Chris Renfroe, came up with an application that detected potential duplicates. These potential duplicates had to be checked manually but students could have changed them enough so as not to appear as duplicates. One of the best methods that had been devised for detecting cheating proved to be taking the list of Accessidentified duplicates and check for duplications among those same students’ Excel projects.

\section{Outcomes and Policies}

The first semester CCPE was used, 54 duplicate projects were detected. CCPE has been used every semester since its creation. The students were informed at the beginning of each semester that any and all technology available might be used to detect duplicates to help deter students from cheating. Despite this warning, however, duplicate submissions were detected every semester and for every project. On the bright side, the number of duplicates did decrease significantly after CCPE's introduction. By spring 
2006, only a couple of duplicates were typically detected for each project. This reduction, however, stemmed as much from changes in policies as from the technology itself.

The biggest policy change that had come about related to the punishment for cheating. Originally, Warner had given students a zero on any project or test where they were found to be cheating. For example, the 54 students that were caught the first time CCPE was used all received a zero for their project. Over time, however, she had come to believe such punishment was insufficient. Specifically, there was no incentive not to cheat by giving students zeros. Students got the same points for getting caught cheating as they did for not turning a project in. Apparently, the shame of getting caught did little to deter some students. The minimal effort required for making an electronic copy and submitting it seemed justified when compared to not turning in any assignment at all and getting a guaranteed zero. Warner therefore decided to give the students an incentive not to cheat. If caught, students would not only lose the points for that project but they would also lose an additional 50 points. In other words, if a particular project was worth 30 points and they were caught cheating, they would lose 80 points.

Over a dozen students were caught submitting improper assignments during spring semester of 2006. Eight of these students were caught submitting duplicate projects for both the Access and Excel project. Each one lost a total of 140 points, representing nearly 3 letter grades. Unless a student was doing high A work, he or she could not recover from losing that many points. And, for the most part, high A students were not the ones that generally turned in duplicate work in the first place.

\section{Current Situations}

Even with a clearly stated, firm and non-negotiable policy on academic dishonesty, Warner found that she was continually being forced to make difficult decisions. For example:

- When three of the students who had submitted duplicate assignments in spring 2006 were confronted, they did not deny that they had turned in a copy of the same project. Instead, they claimed they had done the work together and didn't realize they couldn't collaborate on the projects. Warner directed them to the syllabus and her academic integrity policy. The three students were all on scholarships. None were going to pass because as a result of the policies. Two of them were taking enough other classes during the semester so that they would be able to retain their scholarship. The third student, however, didn't have enough credits to drop ISM3011 and still retain her scholarship. Failing was not an option either. When the students discovered this, the two dropping the course changed their story and claimed that the third student did all the work and they submitted copies of her project file. The third student came to Warner pleading for her not to take away those points. Should Warner relax her academic dishonesty policy to prevent a student from losing a scholarship?

- In a later spring 2006 incident, two student projects were detected as duplicates of each other using CCPE. One student reported that she had lost her USB drive containing her project (after submitting her project). After being questioned several times, the other student claimed to have received a flash drive from a friend with a copy of last semester's project. Warner suspected the first student was telling the truth and the second student was dissembling. She further suspected the second student had found the lost USB drive and copied the project from the drive. Warner never used the same data sets from previous semesters. This prevented a student from submitting a previous semester's project. It also didn't make sense: if the second student copied his project from a previous semester's student's project, why did his project have the first student's name embedded in it? Warner hoped that with a little more questioning, the second student would confirm her suspicions. But did she need to punish the first as well, if he did not? 
- There was the Kathy Careless situation, described in the introduction, which could still escalate. Already, Warner had added a section about erasing projects from lab computers to her policy so as to reinforce her classroom remarks (see Exhibit 1). She had always made it explicit that it was each individual's responsibility to ensure his or her projects weren't left on a public use computer. She further informed her students that they needed to make sure that all copies of their projects were deleted from the computer and that they emptied the recycle bin. Warner had also contacted computer services and had them schedule nightly emptying of the recycle bin and My Documents folder for each computer in the public use labs. Were there other things she needed to do?

The problem with all of these situations was that none of them was truly black and white. In a technology dominated world, however, was it even possible to create a truly universal policy?

\section{Conclusions}

The way Warner handled academic dishonesty had evolved over time. She tried as many things as she could to prevent academic dishonesty and balanced that with detecting it as much as possible while not inhibiting learning or taking too much time away from teaching. Warner's academic dishonesty policy was a work in progress and in reality, students had not lost their project points unless some type of collusion had been proven. However, a few situations, such as Kathy Careless', presented themselves in ways that made Warner rethink her policy. Should she have restored Careless's points? What about the student that lost the USB drive? Should Warner restore this student's points as well?

Beyond the specific situations that needed to be addressed immediately, Warner also had broader concerns. For example, she had started to question her policy on no collaboration. Was she doing the right thing or was she, instead, preventing students from learning? If she allowed collaboration, she could offer fewer help hours but would the students learn as much? This also opened up a broader question of overall course design. Was it possible to develop alternative ways of presenting or testing the material so as to reduce likelihood of cheating without increasing the effort required for enforcement?

Another issue that weighed on Warner's mind was the time and frustration associated with dealing with the problem of cheating. She loved most aspects of her job. Unfortunately, addressing situations such as the ones just described was necessary if she chose to continue enforcing her academic dishonesty policy. The easiest way to alter this balance, of course, would be to stop looking. Warner once had an anatomy teacher tell her that, "people are always going to cheat and you can't stop them." She had come to agree with the first part. Was she ready to concede the second as well?

A number of faculty members had also expressed concerns to Warner relating to where the institution actually stood on these matters. Many of the signals being sent were mixed. On the one hand, the university had subscribed to an anti-plagiarism service, TurnItIn.com, and had encouraged faculty to use it. That seemed to argue for taking a no-nonsense stance on copying and other forms of academic dishonesty. On the other hand, faculty members were not required to use the system, were required to inform students when they were using it, and, in the event cheating were to be detected, the penalties to be applied were still largely determined by individual faculty members and departments. Given the huge amount of effort and risk associated with holding students to account for their cheating, this seemed to implicitly favor a "look the other way" policy. What would happen to the institution's policy when one or more of the parties to a cheating incident threatened to involve the legal system? Warner took the following view: 
Personally, I just assume that if there is an academic policy the university/COBA/department will stand behind it. I try to always be sure that I can prove my case without a shadow of a doubt - or I don't apply the penalty - to try to avoid these problems/legal issues.

Furthermore, Warner wondered if she were being uniquely aggressive in pursing these matters. If so, perhaps her students had a point when they said that they hadn't understood the rules. If common practice was to specify policies, but not to enforce them, could students reasonably conclude that such policies were merely presented as boilerplate, rather than rules that would be actually be enforced, and that were meant to be obeyed? Compounding the situation, her department was going through a serious drought in MIS-major enrollment that had started after the end of the Internet bubble, several years before. Her course was the perfect venue for recruiting future MIS majors. How was her tough stance impacting this recruiting process?

Of course, that last question could also be turned around. Did MIS really want to recruit students who were completely comfortable with submitting work that was not their own? 


\title{
Exhibit 1: ISM 3011 Syllabus
}

\author{
ISM 3011 Information Systems in Organizations 8 Spring 2006 \\ Section 901 - Thursdays 6-8:50 pm and Section 020-Web-Based Version \\ changes from printed version highlighted in green
}

Instructor: Barb Warner

Graduate Assistants: [Omitted]

\author{
Email: bwarner@coba.usf.edu or via Blackboard (Bb) \\ Office: CIS2008 \\ Contact Hours: \\ Mon. 8:30-10:30 am online via MSN Instant Messenger \\ Tues. 12-2 pm BSN2404 (lab) \& 10-11 pm online via \\ MSN \\ Instant Messenger \\ Thurs. 5:15-6 pm BSN1100 (lecture hall before class) \\ and after class in CIS1036 lab as time allows \\ Sat. 8-10am online via MSN Instant Messenger - \\ canceled \\ Email: ism3011@coba.usf.edu or via Bb \\ Office: CIS3008 \\ Lab: BSN2404 \\ Contact Hours: will be posted / distributed during first \\ week
}

\section{Course Description}

A survey of the language, concepts, structures and processes involved in the management of information systems including the fundamentals of computer-based technology and the use of business-based software for the support of managerial decisions. CGS2100 is a prerequisite for this course and it is assumed that you are proficient using Microsoft Excel and Access

\section{Course Materials}

Text: Management Information Systems, 9/e (with Activebook access code); Laudon \& Laudon; Prentice Hall.

\section{Options:}

1) Recommended. Custom version for this class, soft-back, black \& white version of the text with an online access code available at the USF bookstore (\$60) ISBN: 0536153574.

2) Online access only - you can purchase this at www.pearsoncustom.com/usf (\$60)

3) Hard-back color version directly from the publisher at www.prenhall.com, ISBN: 0-131-53841-1. Cost around $\$ 135.00$ and there is no online access code.

4) Used copy - if you can find one, be sure that it is the $9^{\text {th }}$ edition and the access code has not been previously registered with the publisher.

Earphones-required: They can be the very inexpensive kind or borrowed from a portable CD player/iPod.

File Storage: You may need some way of saving/transporting work - it is up to you how you do it. From experience, we strongly recommend a flash/thumb drive. Other options include floppy disk, emailing work to yourself, using USF's online storage, myYahoo briefcase - obviously each option has its own advantages and disadvantages. NOTE: floppy disks \& emailing work are often used by students, but are also unreliable and the cause of lost work. See me with any questions on this.

Optional Materials: Any Level 2 Microsoft Office XP text and/or the text from CGS2100. If you need to refresh your Access or Excel skills - two good books are: Access for Windows 2003, Schwartz, ISBN: 0-321-193938 and Excel for Windows, Langer, ISBN: 0-321-20038-1 - both available at the USF bookstore.

\section{Course Structure/Attendance}

ISM3011 is offered in two sections using two different learning environments; face-to-face and web-based. We offer many opportunities for contact and help as well as class on Thursday nights (students from the web-based section may attend - as space allows). There are three scheduled exams that must be taken on campus (BSN1100) at your section's scheduled meeting time (Thursday night or Saturday morning). All of your work will be turned in online via Blackboard $(\mathrm{Bb})$.

Both sections have a requirement for hours of instruction - whether online or face-to-face. For this reason, you should expect to spend the 3 hours of 'class time' plus the time you would normally spend at home for a 3-credit course (reading, online/face-to-face participation in the discussions, and projects - estimated at another 3-6 
hours). This is just a guideline; you may need more or less time depending on your learning style and experience. Be sure you plan for the time necessary for you to be successful in this course.

One of the biggest documented problems with large lecture and web-based class formats is the lack of contact or help. This is why we offer extensive contact hours during the week via office/lab/IM and email. Take advantage of these contact opportunities. We are trying to provide all the tools for success in this class, but you are ultimately responsible for your own learning experience.

\section{Academic Dishonesty $:$ - Integrity does matter $: ;$}

Copying, plagiarism or any other form of misrepresentation of one's work is cheating - this includes cutting/pasting from the Internet or copying anyone else's projects/assignments. All projects are to be done individually - no group work, discussion, or help except by the 3011 teaching team is permitted. Anyone caught cheating/collaborating on assignments, projects, or exams, in any way, will lose the project/assignment/exam points plus 50 points from their overall score OR receive an F/F in this course (instructor's discretion).

Many assignments are purposely left open-ended to let you be creative and do some critical thinking. All projects end up being unique and we check/grade them carefully as well as use any/all technology available to ensure academic integrity. Each exam includes project questions - if you have not done the project yourself or do not understand the concepts/skills learned, you may not do well on this part of the exam.

Each semester we find similar/copied projects. We apply penalties to all parties involved - no exceptions. Do not let this happen to you. You can help prevent problems by removing your work from all public computers - this includes emptying the recycle bin after deleting any work. It is your responsibility to be sure your project cannot be copied or viewed by anyone else. This includes friends' computers / flash drives / disks.

I do not enjoy the 'academic dishonesty' part of teaching, but I do feel very strongly about honesty/integrity and I do uphold University/my course policies on cheating. Recently, IT professionals were surveyed and the number one attribute they looked for in new hires was integrity (above technical skills). I treat academic dishonesty very seriously and will fail students who cheat on exams or turn in work that is not completely their own. See "Academic Dishonesty" in the Undergraduate Catalog for further discussion.

If you have any questions on this as it relates to individual assignments - please contact me, I'll be glad to discuss this in more detail.

\section{Student Evaluation}

\begin{tabular}{|c|c|c|}
\hline \multicolumn{2}{|c|}{ Activity / Points } & Letter Grades ( no + or - ) \\
\hline $\begin{array}{c}\text { Module 1: Project(s) } \\
\text { Exam }\end{array}$ & $\begin{array}{r}50 \\
100\end{array}$ & \multirow{4}{*}{$\begin{array}{c}450-500 \text { points }=90-100 \%=\mathrm{A}(\underline{\text { superior } \text { work })} \\
400-449 \text { points }=80-89 \%=\mathrm{B}(\text { excellent work }) \\
350-399 \text { points }=70-79 \%=\mathrm{C}(\text { average work }) \\
325-349 \text { points }=60-69 \%=\mathrm{D} \text { (below average work) } \\
\text { below } 325 \text { points }=\text { below } 60 \%=\mathrm{F} \text { (failing work). }\end{array}$} \\
\hline $\begin{aligned} \text { Module 2: } & \text { Project(s) } \\
& \text { Exam }\end{aligned}$ & $\begin{array}{l}100 \\
100\end{array}$ & \\
\hline $\begin{array}{c}\text { Module 3: } \text { Project(s) } \\
\text { Exam }\end{array}$ & $\begin{array}{r}50 \\
100\end{array}$ & \\
\hline Total & 500 & \\
\hline
\end{tabular}

All work/assignments/announcements are posted on Blackboard.

We know grades are important and try to be very attentive while grading and recording grades. Please do your part by monitoring your own grades and keeping all graded correspondence/returned work. Any grade issues should be addressed within 3 weeks of the due date.

NOTE: Undergraduate students who enter USF under the 2001-2002, or later, catalog are required to earn a grade of C-, or better, in every undergraduate core class and an overall GPA of 2.0 for all undergraduate core classes.

\section{Assignments, Exams, Late \& Make-up Work}

A schedule for the course is included; please note all due dates. Acceptable, written documentation (doctor's notes, etc.) will be required for you to make up an exam or hand in late work without penalty.

- $\quad$ Projects must be uploaded successfully to $\mathrm{Bb}$ by midnight on the due date. Late work is accepted until the following Monday at midnight (5 point penalty for each late project). Each project includes instructions on 
checking your upload to be sure the work was submitted correctly. Work that is submitted to Bb incorrectly and cannot be opened or graded for any reason is considered late and can be resubmitted with the 5 point penalty ONLY IF we can verify that it has not been altered after the Monday late date (you must save a copy to disk/CD when you submit it). An illness/event on or around the due date is not a valid excuse for late projects. You have several weeks to work on each project and we recommend that you turn them in early!

- Participation/Extra Credit - is available in each module. This takes the place of any curve or any extra consideration if you are 'close' to the next grade level. Activities will be described in the individual modules (on Bb).

- 'Technology problems', including bad disk, bad file, bad file name, don't know how to upload to Bb correctly, locked files, lost work, etc. are not valid excuses for late/missing work - they are just part of using computers $:$. Ask questions, get help, and do your work early and check that assignments are submitted correctly so the inevitable computer problems will not lead to missed points. We offer many contact hours each week to help you with this.

- $\quad$ Exam procedures will be listed on $\mathrm{Bb}$ and include details on how they will be administered and what you may bring to the exam. Please review the exam procedures before each exam. All exams taken early or late will be essay in form - unexcused late exams will have a 10 point penalty assessed.

\section{Incomplete Policy}

An 'l' grade may be used for situations where a student has an unforeseeable emergency at the end of the semester and only has a small part of the course to complete. It is not to be used because a student is busy or is not doing well. Students in these situations should withdraw from the class or risk receiving a poor/failing grade. An incomplete grade is given only in extreme circumstances, with written documentation.

Last day to withdraw from a class without penalty is Friday, March $24^{\text {th }}$.

\section{Religious Holy Days}

Students who must miss a scheduled exam time due to the observation of a major religious observance must provide notice of the date(s) to the instructor, in writing, during the first 2 weeks of class.

\section{Students with Disabilities}

Every effort will be made to accommodate students with disabilities, in accordance with arrangements coordinated with Student Disability Services. Any student with a disability should notify the instructor, on an individual basis, during the first two weeks of class.

\section{Technology: Blackboard (Bb) / Email / MSN Instant Messenger (IM) / Activebook}

This is an information systems class and we will be using technology/information systems as well as learning about them.

Bb - All class announcements and class materials are on Bb. CHECK Bb FREQUENTLY (Bb is your friend...) To use $\mathrm{Bb}$ you must go to my.usf.edu and signing in using your USF NetID and Password. If you are a new user or have forgotten your password, instructions/links are available from my.usf.edu to help you. Once you are signed onto $\mathrm{Bb}$, familiarize yourself with the course website. Free classes in $\mathrm{Bb}$ and other technologies are available at http://www.acomp.usf.edu/training.html or stop by/email//M/Chat and we'll be glad to answer any questions. A back-up website is available at www.coba.usf.edu/departments/isds/faculty/warner/ism3011 for use as needed.

\section{Email}

Instructor initiated: Most email is sent via Bb, which is tied to your university/student email account. It is your responsibility to change your USF email 'preferences' if you want to forward email to a different account. This can be done at the UNA login page: una.acomp.usf.edu or on the Bb Welcome page.

Student Initiated: You can email us via Bb or directly from your own email account.

- If emailing from your own account, please send email to bwarner@coba.usf.edu (instructor) or ism3011@coba.usf.edu (TAs) and please include your name and section in the subject area.

- If using the Bb-based email for our class - ALL FIELDS MUST BE FILLED IN FOR THE EMAIL TO BE SENT, if your email is successfully sent, a confirmation page will be displayed and you will receive a confirmation email.

- Note: I cannot accept any projects vial email - my email server blocks them. All work should be submitted via $\mathrm{Bb}$.

IM - MSN Instant Messenger is also used for communication. You can sign up for IM at www.msn.com and click on 'Messenger' and follow the instructions or you can use a web based version (doesn't require you to download any files) at webmessenger.msn.com Our IM addresses are as follows:[Omitted from the case] 
DO NOT SEND EMAIL TO THESE ADDRESSES - THEY ARE FOR IM ONLY

If you have any questions or need some quick IM lessons - please stop by lab or office hours.

ActiveBook - this allows you to access your text \& supplements online. Your textbook has a cardboard insert included with your access code for the ActiveBook, as well as instructions. Use the 'Online Text' menu item in $\mathrm{Bb}$ or go to www.pearsoncustom.com/usf to get started.

Register and then sign on and familiarize yourself with this site and the online features available. If you need help come into lab/office hours or contact Prentice Hall technical support at 1-800-677-6337.

Other Technology - New technology adventures/exercises are often available and will be part of the extra credit offered (not required).

\section{Getting Started / Doing well in the course:}

- Review this syllabus - ask questions!

- $\quad$ Review the 'Getting Started' section on Blackboard - ask questions!

- $\quad$ Print out \& keep the Lab/Help Schedule from Bb, if you don't already have a copy. You can find it in the 'Getting Started' section.

- $\quad$ Print out/Review the Module 1 page from $\mathrm{Bb}$ - this tells you the chapters we are covering, projects due dates, etc. It also gives advice on how manage the course work.

- Do your work early - don't procrastinate. Email/IM or come into lab/office hours with questions. 
ISM 3011 Information Systems in Organizations Spring 2006 Schedule Sections 020 (Web based/Saturday) \& 901 (Thursday night)

Week (Mon-Sat)

- Class Information/Syllabus, Chapters 1-2 Overview - Intro to Information Systems

Week 1

January 9 - 14

o Section 901, Thursday, 1/12, BSN1100@6pm

o Section 020, Saturday, 1/14, BSN1100@9am

- $\quad$ Begin work on Module 1

- $\quad$ Read Chapter 1 for background material

Week 2

January 16 - 21

- Chapter 2 - Info Systems in the Enterprise

Week 3

January 23 - 28

- Project Skills Overviews

Week 4

Jan $30-$ Feb 4

- $\quad$ Ch 3 - Info Systems, Organizations, Management, and Strategy

Week 5
Feb $-6-11$

Week 5
Feb $-6-11$

Week 6

Feb 13-18

Week 7

Feb 20-25

Week 8

Feb 27 - March 4

Week 9

March 6-11

Week 10

March $13-18$

Week 11

March 20 - 25
- Ch 4-E-Commerce

- Ch 5 - Ethics \& Hardware/Software Overview

- All Module 1 work due (projects/forums) by Wednesday, 2/8/06, 11:59 pm (all submitted via $B b$ )

\section{- Exam 1}

o Section 901, Thursday, 2/16 @ 6pm in BSN1100

o Section 020, Saturday, 2/18 @ 9am in BSN1100

No TA Lab/Office/Online hours - Tues through Saturday of this week

- $\quad$ Begin Module 2 work - Project Skills Overview in class

- Review Exam / Project Grading

- $\quad$ Online Lecture (all classes) - Chapter 6 - Infrastructure

- $\quad$ Ch 8 - Telecommunications, Networks, Internet \& Ch 9 - Wireless

- $\quad$ Ch 7 - Data Resources

Communications

- $\quad$ Spring Break :)

- $\quad$ Ch 10 - Security Issues

- $\quad$ All Module 2 work due (projects/forums) by Wednesday, 3/22, 11:59 pm (all submitted via Bb)

- $\quad$ Friday, 3/24 - last day to withdraw from the class without penalty

Week 12

March 27 - April 1

\section{- Exam 2}

o Section 901, Thursday, 3/30 @ 6pm in BSN1100

o Section 020, Saturday, 4/1 @ 9am in BSN1100

- No TA Lab/Office/Online hours - Tues through Saturday of this week

- $\quad$ Project Skills Overview

Week 13

April 3 - 8

Week 14

April $10-15$

Week 15

April 17 - 22

Week 16

April 24-28

Final Exam
- $\quad$ Review Exam / Project Grading

- $\quad$ Begin Module 3 work

- $\quad$ Online Lecture (all classes) - Ch 12 Managing Knowledge

- Ch 14 Redesigning the Organization

- $\quad$ Ch 15 Understanding the Business Value of Systems \& Managing Change

- $\quad$ All Module 3 work due (projects/forums) by Wednesday, 4/19, midnight (all submitted via $\mathrm{Bb}$ )

- $\quad$ Exam Review - Thursday, 4/27, BSN1100, 6pm (will also be posted online for section 020)

- TA/Lab/Online hours end on Monday, 4/24

Covering all material / projects

- $\quad$ Section 020 : Saturday, April 29 @ 9am in BSN1100

- Section 901 : Thursday, May 4 @ 6pm in BSN1100 


\title{
Exhibit 2: Access Project Instructions
}

\author{
M2-Access Assignment - ISM3011 - Spring 2006 (50 pts)
}

Submit via Blackboard (Bb) by Wednesday, March 22, 2006 by midnight.

Come into lab/office hours if you have problems with any of this. Refer to the syllabus on Academic Dishonesty and group/individual work and allowable help for all projects - also remember it's your responsibility to protect your work; delete it \& empty the recycle bin if you work on public/lab computers.

Scenario: You are creating a sample database for a small chain of pharmacies. The database will contain 3 tables; one with pharmaceutical info, one with store info, and one with sales info. You will create the database, tables, a form, queries and a report.

\section{Part 1 - Getting Started / Database}

- Review the project - look over the 2 excel spreadsheets that are provided as well as all the instructions to get familiar with the data \& what is required. Watch the following Access Tips on Bb: Importing Importing multiple field primary key $\sim$ Creating a relationship between tables $\sim$ Formatting a Query $\sim$ Sorting a Query-Formatting Fields within a Query $\sim$ Queries-Basic Parameter $\sim$ Queries-Calculation Fields $\sim$ Queries-Top Values $\sim$ Reports - grouping / sum/ average \& design view Validation Techniques and any tips from the module 1 assignment you need to review.

- Create a blank database (1pt) and name it your last name followed by your initials and_2AC.mdb (ex. WarnerBL_2AC.mdb) Note: .mdb is the extension Access will add to your database file name.

\section{Part 2 Tables (11pts)}

- $\quad$ Pharmaceuticals - Import the pharmaceutical information from the Excel file 'M2-AccessPharmaceuticals.xls' into an Access table (named 'Pharmaceuticals').

0 The primary key (unique identifier for each record) should be the UPN Code.

o Use data validation to be sure that the cost of any new item added to the table does not exceed $\$ 9.00$. Display an error message if this occurs.

- PharmStores - There are 10 stores in this chain. Some of their data is listed below. Create a table to hold this data - call it 'PharmStores' and make up the rest of the data for each store (Address, Zip, Phone, and Manager).

o The primary key should be the Store ID

o Set up an input mask for the telephone number

o Set the Store name and manager's name to be required fields

0 Enter the data below for the 10 stores and make up the data for the address, zip, phone, and manager fields. Add your name as one of the managers.

\begin{tabular}{|c|c|c|c|c|c|c|c|}
\hline Store ID & Store Name & City & State & Address & Zip & Phone & Manager \\
\hline DSL-100 & CVP - Southeast & Tampa & $\mathrm{FL}$ & & & & \\
\hline FDS-200 & Wal-Shop & Bethesda & MD & & & & \\
\hline DJT-101 & Tampa Supplies & Tampa & $\mathrm{FL}$ & & & & \\
\hline DSL-455 & Eckwoods & Charlotte & NC & & & & \\
\hline FDS-201 & Browns & Atlanta & GA & & & & \\
\hline DJT-143 & CBC Pharmacies & Jacksonville & $\mathrm{FL}$ & & & & \\
\hline DSL-102 & Greens & Atlanta & GA & & & & \\
\hline FDS-223 & Southern CVP & Miami & $\mathrm{FL}$ & & & & \\
\hline DJT-103 & Gulf Coast Pharmacy & Tampa & FL & & & & \\
\hline DSL-403 & Seffner Pharmaceuticals & Seffner & FL & & & & \\
\hline
\end{tabular}

- PharmSales - Import the sales info from the excel file, 'M2-Access-PharmSales.xls' into an Access table named 'PharmSales'. 
o The primary key should be a combination of Month, Store ID, and UPN Code (a multiple field primary key).

- All tables

o Make sure all data types AND field sizes are reasonable (not default values) - watch the online Access 'Tips' for more info on this.

o Add data descriptions for all fields.

o No additional fields/tables should be added to the project at any time.

\section{Part 3 (3 pts) - Relationships}

- Create a relationship between the 3 tables. The Store ID field should join the PharmStores and PharmSales tables. The UPN Code field should join the PharmSales and Pharmaceuticals tables.

\section{Part 4 (5 pts)-Form}

- Create a form for the PharmStores table - include all fields. If you use the wizard, select 'Standard' for the style so you can modify the background.

- Format the form so that it has a header section (within the form) so the form name and your name is displayed in this header section when the form is opened. Use a color, large font (16 pt at least) for the headings.

- Add a background color to the form.

- $\quad$ Make the form look professional.

- $\quad$ Test the form by adding 2 new stores. Make up all the information for the fields (don't leave any fields blank) and add your name as the manager of both stores. Check the datasheet view of the table to be sure the new stores were added correctly.

Part 5 (12 pts)- Queries - Create the following queries: (Queries should work even if new data is added to your tables)

- Q1-Using the parameter feature, allow the end user to enter a state and see all the sales records for that state. Include (in any order that makes sense) Store ID, Month, UPN Code, Units Sold, and State. Sort by Store ID (ascending) and within that, by Units Sold (descending). Name this query what ever you'd like, but be sure it starts with "Q1-“ (example: Q1-Sales by State)

- Q2-Create a query that shows the top 8 selling pharmaceuticals in the PharmSales table (based on Units Sold). Use the top values function in Access and include the UPN Code, Name, Store ID, Month, \& Units Sold for each. Sort in descending order by Units Sold. Name your query what you'd like, but be sure it starts with “Q2-“ (example: Q2-Top8)

- Q3-Use a query and two calculated fields (must be done in the query). Calculate the profit per unit and the markup percentage for each item (the \% it is marked up based on the cost). Format the profit per unit in a currency format (\$ plus 2 decimal places) and the markup percent as a \% with 1 decimal place. Include the UPN Code, Name, Cost, Selling Price, Profit per Unit and Markup \%. Sort in descending order by Cost. Name your query as you'd like, but be sure it starts with "Q3-“ (example: Q3-Markup)

- Q4-Create a query that calculates the markup \%'s for each item but only displays the items in inventory with a markup greater than or equal to $200 \%$. Include the same fields as in Query 3. Sort in descending order by Markup \%. Once this is working, format the query datasheet so that it has a background color and colored gridlines and any additional formatting features you'd like. Again, name it what you'd like - but make sure it starts with “Q4-“ (example: Q4-High Markup)

- $\quad * *$ Check all queries for reasonable/accurate results.

\section{Part 6 (8 pts) - Reports - Create a Sales report:}

- First create a query with the following fields: City, Store ID, Store Name, Manager, UPN Code, (Pharmaceutical) Name, Units Sold. Name the query starting with "Q5-“"

- Create a Sales Report from the Q5- query, include the following:

o Group by City and then by Store ID

o Within the grouping, sort by Units Sold (descending) and then by UPN Code (ascending)

o Include Summary Options by Group (sum of all items sold and detail)

o Make sure the report fits on one page in width (will be several pages in length)

o Add color fonts to your report - all headings (not blue or black).

o Add your name in the Report header. 
o Make sure all headings/data are complete (not cut-off). You should have several detail headings with more than one word (Units Sold). Wrap each of these onto 2 or more lines in the page heading section

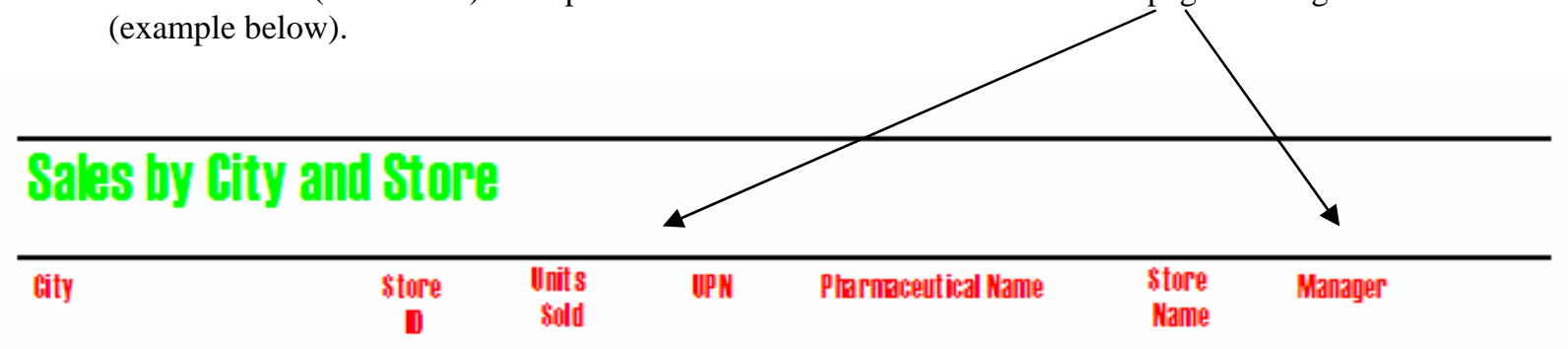

Atlanta

DSL-102

o Look over your report and make sure it looks good and makes sense - spend some time/effort on it.

o Name your report whatever you’d like, but have it start with “R1-“(example: R1-Sales Report).

\section{Part 7: Submit \& Check}

- Read and follow the instructions in the PROJECT section of Bb on uploading and checking your upload. If you follow these instructions you can ensure that your project is uploaded correctly - and you've put the appropriate info in the $\mathrm{Bb}$ comment section (required). If you have problems - come in to any lab/office/online hours (or before/after class) to get help. If your project doesn't upload correctly, it will be considered late and be assessed the late penalty - even it was finished on time. If it is modified after the late date, it can’t be accepted.

*** Final Note! We can't possibly anticipate every situation you may encounter while using Bb, the Activebook, the Internet, and your PC. That is why we have so many office/lab/chat/IM hours. Please start all of your work early and get help when you need it. Technology problems are not valid excuses for late/missing work.

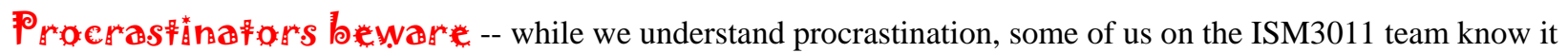
well -- it can really impact your grade negatively in this class. Don't wait until the last minute/day/hours to do your work - technology is not kind to those who put things off.... and the labs may be too crowded for you to get the help you need.

\section{HELP! HELP!! For help with any of the required project skills, refer to:}

- Tips/FAQs on Blackboard - they will explain/demonstrate the required skills and an Access Basics review

- Access Help Features

- $\quad$ Reference Book (optional material listed on syllabus)

- Thursday night class and/or Online Notes

- Online discussions or chat/office hours or come to lab (after you come to class or have watched the Tips on Bb we'll be happy to answer specific questions you have.)

- Do not discuss/collaborate with other students - part of the learning process is to 'play' with Access and figure out how to approach/complete the project.

*** We can't possibly anticipate every situation you may encounter while using Bb, the Activebook, the Internet, and your PC. That is why we have so many office/lab/chat/IM hours. Please start all of your work early and get help when you need it. Technology problems are not valid excuses for late/missing work 


\section{Additional Access Notes:}

$\rightarrow \rightarrow$ COPYING YOUR DATABASE: If you need to copy your database to a floppy disk or another folder within your computer, you will have to close your database and then use the 'COPY' and 'PASTE' commands in Windows to copy it. You cannot have the database open and try to 'SAVE AS' - that doesn't work with Access.

$\rightarrow \rightarrow$ DATABASE SIZE: If your database starts getting too large and you're afraid it's not going to fit on a floppy disk, you can copy it to your computer's desktop or My Documents and then compact it (it's best not to compact the database while it is still on the floppy disk). To compact it, open your database in Access and click on the "Tools" menu item and choose "Database Utilities" and select "Compact and Repair Database”. It's best not to store your database on a floppy disk. 


\section{Exhibit 3: Office, Lab, and Online Hours Schedule}

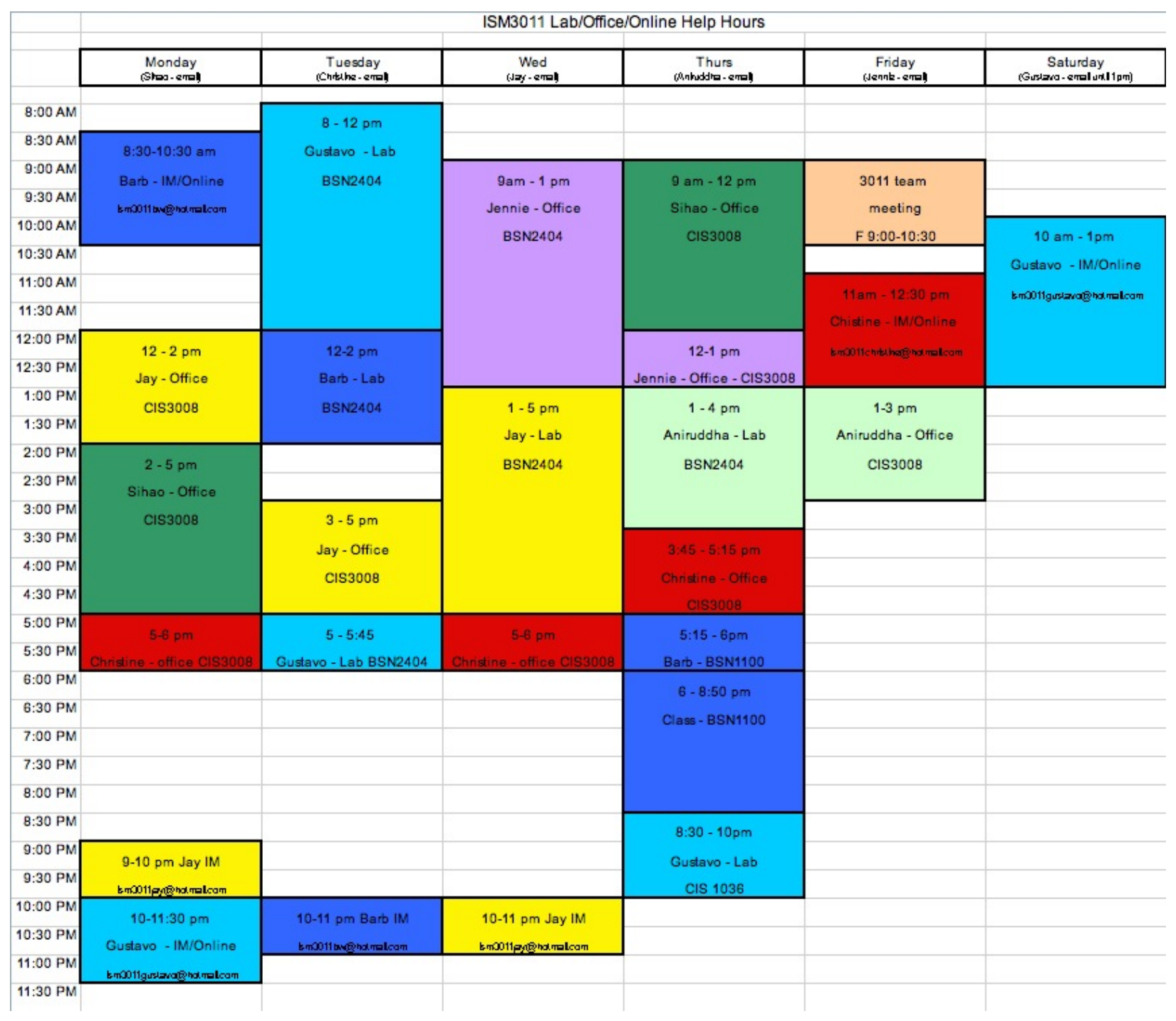




\section{Exhibit 4: Access and Excel Tips}

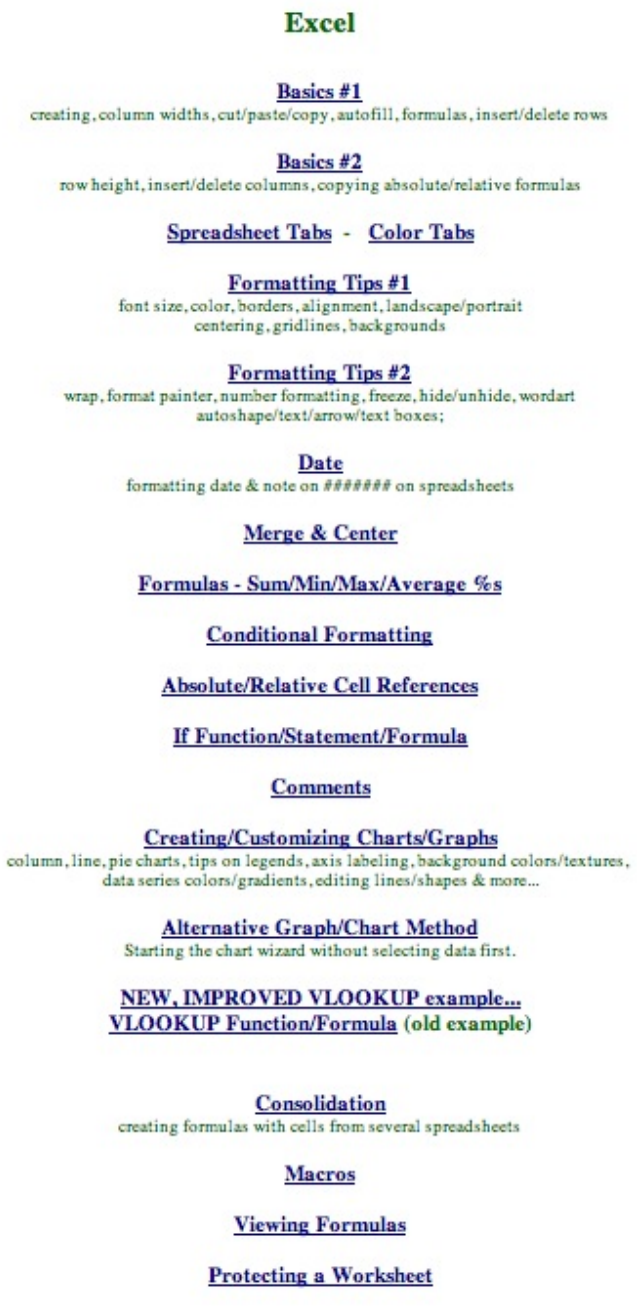

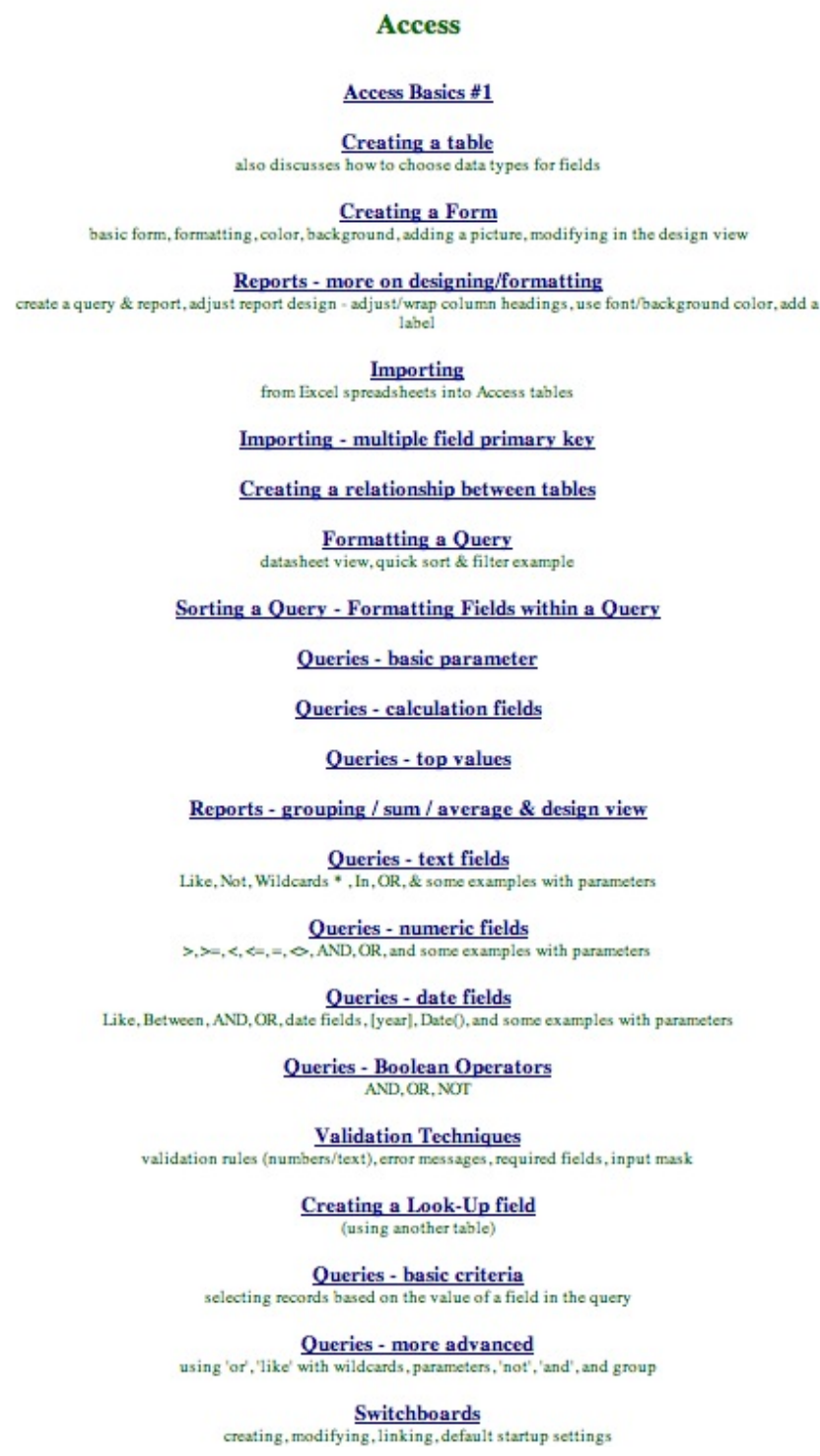




\section{Exhibit 5: CCPE Screen Shots}

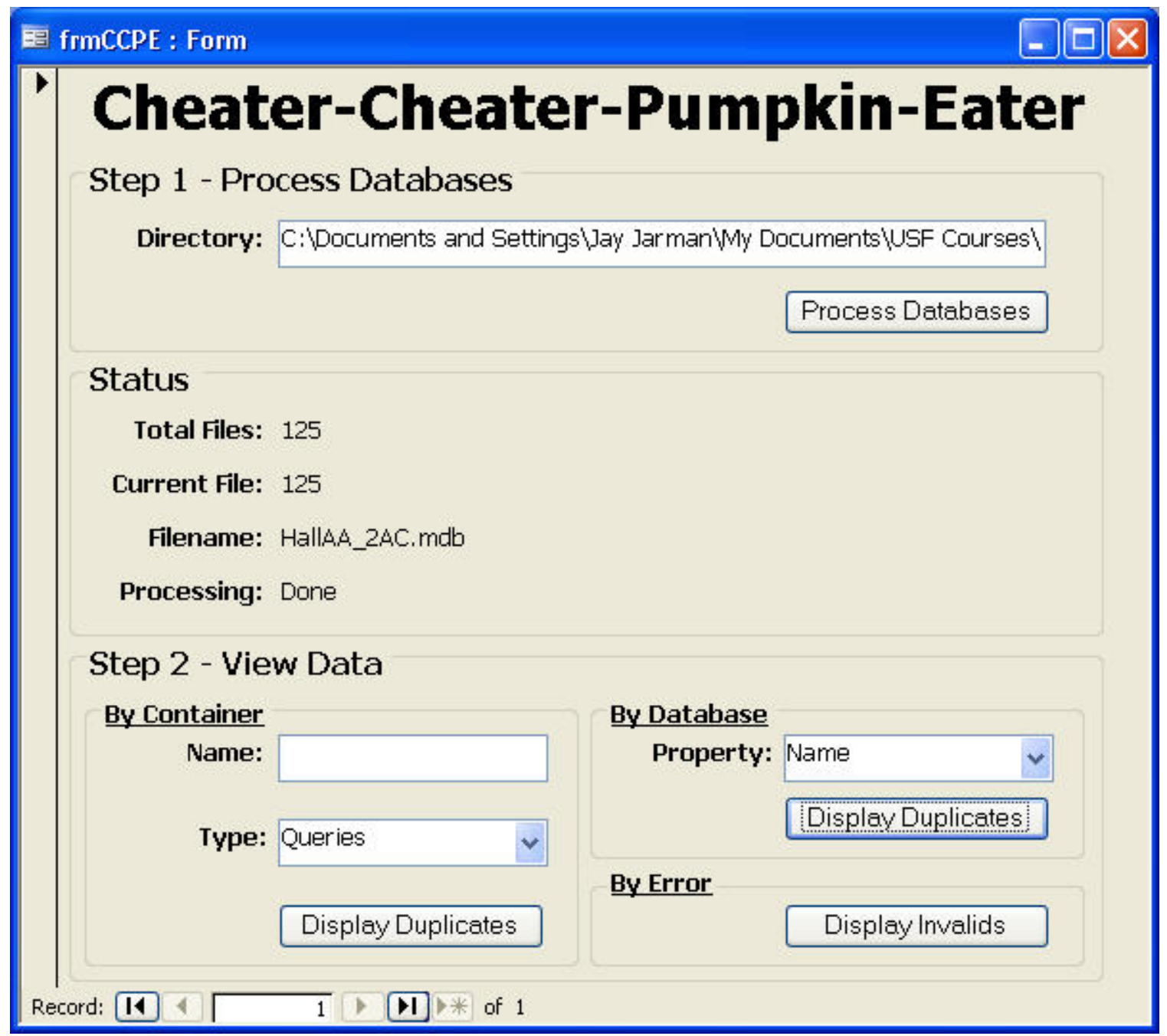

Fig 5-1: Main program window after database files have been selected and compared

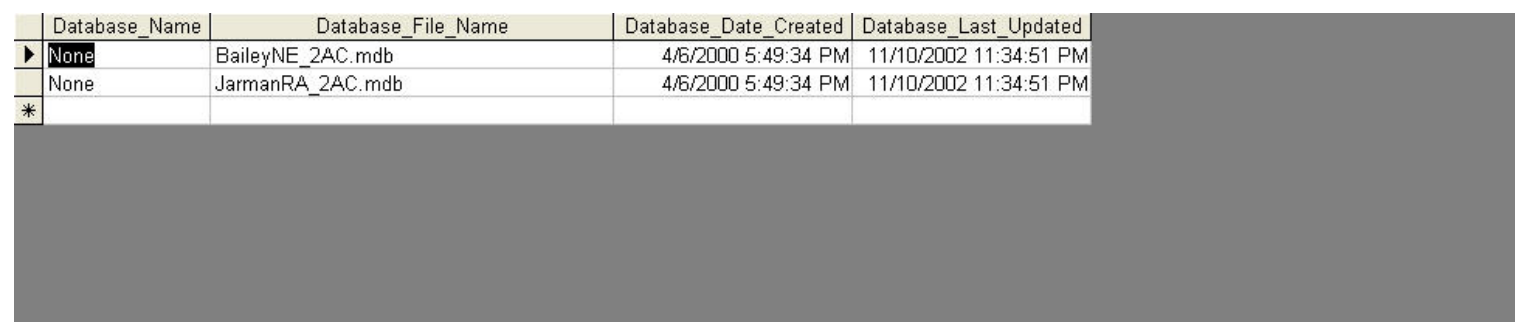

Fig 5-2: Window that appears after Display Invalids is clicked. 


\section{Biographies}

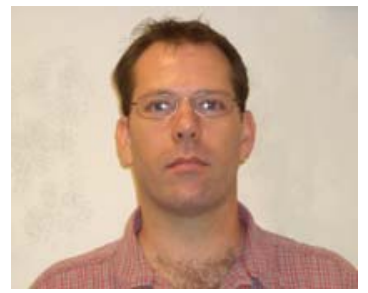

Raymond Jarman is a Masters student in the Management Information Systems program in the Information Systems and Decision Sciences department at the University of South Florida. After serving 8 years in the US Air Force, he obtained his undergraduate degree in Computer Science from East Tennessee State University. He has nearly 20 years experience in developing and managing information systems as well as experience in teaching and developing IT courses for software companies. He has been a TA for ISM 3011.

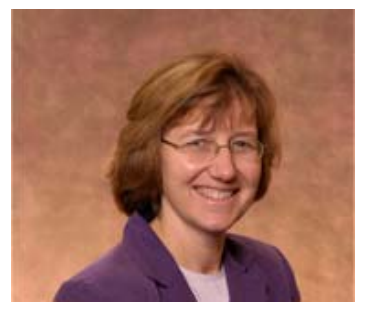

Barb Warner is an Instructor in the Information Systems and Decision Sciences department of the University of South Florida. She holds an undergraduate degree in Computer Science/Mathematics and a Master's degree in Management Information Systems from the University of Arizona. She has worked as a systems programmer and as a director of MIS. She has taught undergraduate computer science, MIS, and mathematics courses at various universities and community colleges since 1982 and has interests in the use of information systems and technology-enhanced instructional methods to increase interaction, commitment, and persistence of students enrolled in large class face-to-face and distance learning courses.

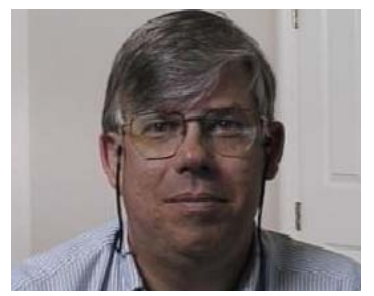

Grandon Gill is an Associate Professor in the Information Systems and Decision Sciences department at the University of South Florida. He holds a doctorate in Management Information Systems from Harvard Business School, where he also received his M.B.A. His principal research focus is in the area of IS education, and he has published many articles describing how technologies and innovative pedagogies can be combined to increase the effectiveness of teaching across a broad range of IS topics. Currently, he teaches programming, database and managerial courses to both undergraduate and graduate students. 